\title{
POLISH NOTES ON MOSCOW DOCUMENTS OF THE TIME OF TROUBLES: HISTORICAL AND LINGUISTIC ANALYSIS
}

\author{
Natalia V. Eilbart \\ Herzen State Pedagogical University of Russia, Saint Petersburg, Russian Federation
}

\begin{abstract}
Introduction. The article analyzes Polish markings made on documents of Moscow origin during the Time of Troubles. Materials. For analysis we took documents stored in the archives of St. Petersburg Institute of History of the Russian Academy of Sciences (petitions of nobles, merchants and peasants to Moscow princes, King Sigismund III and Prince Vladislav), as well as documents from the Smolensk archive, which are located in the State Archives of Sweden (Riksarkivet). Two categories of documents stand out: petitions of Moscow nobles addressed to King Sigismund III and Prince Vladislav, as well as other documents that fell into the hands of the Poles after the fall of Smolensk in 1611. We included in the last category the documents of Smolensk Provincial Prikaz and the personal archive of voevoda M.B. Shein as well. After a long stay in the territory of the PolishLithuanian Commonwealth, a part of The Smolensk Archive came to Sweden during the Polish-Swedish war (the "Flood"), a part settled in the continental Europe, later re-entered the territory of Russia due to the activities of the Archaeographic Commission. Methods. We used the methods of comparative linguistic analysis, the method of comparison, the system method, as well as the narrative and historical-genetic methods. Results. Polish inscriptions on documents of Moscow origin testify to the great influence of the Russian language on Polish and the appearance of numerous Russisms in the Polish language.

Key words: the Time of Troubles, Smolensky archive, Sigismund III, Prince Vladislav, polonizm, Russisms, Polish notes.

Citation. Eilbart N.V. Polish Notes on Moscow Documents of the Time of Troubles: Historical and Linguistic Analysis. Vestnik Volgogradskogo gosudarstvennogo universiteta. Seriya 4, Istoriya. Regionovedenie. Mezhdunarodnye otnosheniya [Science Journal of Volgograd State University. History. Area Studies. International Relations], 2019, vol. 24, no. 2, pp. 55-61. (in Russian). DOI: https://doi.org/10.15688/jvolsu4.2019.2.6
\end{abstract}

УДК 930.272

Дата поступления статьи: 27.09.2018

ББК 63.3(2)4

Дата принятия статьи: 15.03.2019

\section{ПОЛЬСКИЕ ПОМЕТКИ НА МОСКОВСКИХ ДОКУМЕНТАХ ПЕРИОДА СМУТЫ: ИСТОРИКО-ЛИНГВИСТИЧЕСКИЙ АНАЛИЗ}

\author{
Наталия Владимировна Эйльбарт \\ Российский государственный педагогический университет им. А.И. Герцена, \\ г. Санкт-Петербург, Российская Федерация
}

\footnotetext{
Аннотация. В статье проводится анализ польских пометок, сделанных на документах московского происхождения в период Смутного времени. Выделяются две категории документов: челобитные московского дворянства на имя короля Сигизмунда III и королевича Владислава, а также иные документы, попавшие в руки поляков после падения Смоленска в 1611 году. К последней категории мы отнесли документы Смоленского воеводского приказа и личный архив воеводы М.Б. Шеина. После длительного нахождения на территории Речи Посполитой часть «смоленского архива» попала в Швецию во время польско-шведской войны («Потопа»), часть осела на территории континентальной Европы, в последующем вновь попала на территорию России благодаря деятельности Археографической комиссии. Польские надписи на документах московского происхождения свидетельствуют о большом влиянии русского языка на польский и появлении в польском

() языке многочисленных русизмов.
} 
Ключевые слова: Смутное время, Смоленский архив, Сигизмунд III, королевич Владислав, полонизмы, русизмы, польские пометки.

Цитирование. Эйльбарт Н. В. Польские пометки на московских документах периода Смуты: историколингвистический анализ // Вестник Волгоградского государственного университета. Серия 4, История. Регионоведение. Международные отношения. - 2019. - Т. 24, № 2. - С. 55-61. - DOI: https://doi.org/10.15688/ jvolsu4.2019.2.6

Введение. В период Смутного времени ряд документов, вышедших из недр московского делопроизводства, оказались разными путями в руках польской королевской канцелярии и были ею не только сохранены, но и тщательно просмотрены, рассортированы и прокомментированы. Комментарии эти, вынесенные в отдельные надписи на оборотной стороне документов, достойны отдельного изучения и отдельной статьи, поскольку в них отразилось своеобразное «польское видение» отраженной в документе проблемы и отношение к ней. К тому же они явственно показывают, насколько быстро происходило «вживание» московской делопроизводственной лексики в польский язык, благодаря чему можно предположить, что в условиях единого польско-литовско-московского государства, о котором так мечтали поляки, вполне мог возникнуть общий, понятный обеим сторонам и составленный из смеси заимствованных друг у друга терминов канцелярский язык.

Материалы и их лингвистический анализ. Нами просмотрены несколько категорий документов, русские тексты которых были в некоторых случаях опубликованы еще императорской Археографической комиссией, однако без учета присутствующих на них польских надписей $[1 ; 7]$. К первой категории мы сочли нужным отнести поступающие в королевскую канцелярию документы с московской стороны в период с 1610 по 1611 г., когда номинально на русском троне находился королевич Владислав. Разумеется, львиная доля этих бумаг являлась просьбами и челобитными на имя короля и его несовершеннолетнего сына от новых русских подданных, считающих Владислава законным царем. При прочтении этих документов обращает на себя внимание и то, что в русский язык довольно быстро входит польская традиция обращения к монаршей особе. Ранее по отношению к правителю мы встречаем такие варианты обращения, как «царю, государю и великому князю Борису Федоровичу» (челобитная дворцовых крестьян Федора Данилова и Наума Федорова царю Борису Годунову) [10] или более расширенную форму «великому государю царю и великому князю Дмитрию Ивановичу всея Руси самодержцу» (титулатура Лжедмитрия I). В более ранних челобитных на имя Сигизмунда III и Владислава используется еще обращение по московской традиции «великому государю королю Жигимонту» (челобитная «торгового человека» Оверкия Сысоева) [21], однако позже польская традиция называть государя «наияснейшим» четко просматривается во всех личных обращениях россиян. Смоленский дворянин Василий Матвеевич Ржевский, прося Сигизмунда и Владислава вернуть ему и его родственникам поместья в Смоленском и Дорогобужском уездах, отнятые царем Василием Шуйским, обращается так: «Наияснейшему великому государю Жигимонту, королю польскому и великому князю литовскому и великому государю нашему королевичу Владиславу Жигимонтовичу» [17], такая же форма обращения присутствует на челобитных к королю и королевичу Григория Дымова [15], Ивана Горихвостова [11], Федора Меньшого Перфурьева [20]. Мы полагаем, что составленная нами выборка из сохранившихся документов этой категории отражает довольно четкую тенденцию языковой интеграции, интенсивно проявлявшуюся во время Смуты.

В то же время польские пометки, сделанные секретарями Сигизмунда III для доклада монарху, свидетельствуют о «врастании» некоторых московских терминов в неизменном виде в польское делопроизводство. Разумеется, прочтением «московских бумаг» занимались в королевской канцелярии почти исключительно лица литовского происхождения, и по понятным причинам они не трудились найти в польском языке аналоги тех или иных терминов, они попросту шли по более легкому пути и озвучивали русские определения, 
довольно быстро усваиваемые поляками, в дальнейшем без перевода понятно было, о чем шла речь [при этом следует упомянуть также, что в русских именах и фамилиях поляки продолжали делать ошибки, либо записывать русские имена на польский лад (например, имя Андрей писалось в полонизированном варианте Анджей (Andrzey)]. Прежде всего, в польский обиход входит само слово «челобитная», которое польские канцеляристы пишут как «czołobitna» [27], иногда на обороте этих документов появляется даже сокращение в виде «czb». Разумеется, чаще всего у короля и королевича просили земель и денег, а посему слово поместье (pomieście) отныне становится в польском лагере понятным всем [например, на обороте челобитной смоленского дворянина Ивана Полаева имеется краткое резюме королевского секретаря: «Prosi o swoie stare pomieście» («просит свое старое поместье»)] [31]. Вопросы о денежном жаловании и поместном окладе также нередко становятся предметом просьб, а посему относящиеся к ним исконно русские определения без перевода входят в польский документооборот. Так, вышеупомянутые уже смоленские дворяне Ржевские просят короля и королевича разрешения служить по своему выбору, а также «о пожаловании денежным жалованьем и поместным окладом», о чем королевский секретарь делает пометку на обороте «о pożałowanie dzienieżnym żałowaniem y pomiesnym okładem», таким образом записывая русские слова по правилам польского правописания [22]. Судя по всему, все нюансы этих вознаграждений были полякам известны, поскольку когда в одном из последующих прошений другие представители семьи Ржевских просят Сигизмунда и Владислава о «денежном четвертном жаловании», в королевской канцелярии делают пометку следующего характера: «роżałowanie pomiesnym okładem y denieżnym czetwertnym żałowaniem» [16]. На другом же прошении, поданном в королевский лагерь под Смоленском Григорием Пыхочевым о пожаловании его «поместьем и 60-ю четвертями в свой оклад» в том же роде отмечено: «60 czetwierci w swoy okład», что также является только записанной по правилам польского языка русской фразой [19]. В данной группе документов, попавших в королевскую канцелярию и помеченных секре- тарями, встречаются также иные разнообразные русизмы, как, например, в просьбах тех же Ржевских «пожалование кормом» («pożałowanie kormem») [12], «подьячий» («poddiaczy») [18], «мельницы» («mielnice») [14].

Второй выделяемой нами категорией московских документов, сохранивших на себе польские пометки времен Смуты, являются бумаги, изъятые поляками из архива Смоленского воеводского приказа после падения города в 1611 году [3]. Мы полагаем, что польская сторона сохранила лишь те документы, которые имели для нее хоть какое-нибудь значение, остальная же часть, скорее всего, была просто ликвидирована. О том, что прежде всего интересовало поляков, мы можем судить по пояснительной записке, сделанной рукой того неизвестного, кто некогда разбирал и систематизировал эти бумаги: «Свод московских документов, в котором разные московские письма, список людей, что были на царском жалованье во время войны, список людей во время осады Смоленска и что у кого имелось из живности, различные письма Шеина царю и новости от шпионов, декреты дела посадских людей перед Шеиным в Смоленске, кои все письма имеют наверху свои подписи» [29]. Среди надписанных поляками документов значатся, например, бумаги с подробным описанием Смоленской крепости или «Смоленского замка», прежде всего башен и ворот, почти поименные списки защитников той или иной его части, наличие пушек и другого вооружения [8]; списки тех, кому «давали царский хлеб», «для хлебной раздачи» [польские пометки также в неизменном виде воспроизводят эти русские определения («carski chleb», «dla rozdaczy chlebney»)] [2; 28]; жалобы посадских людей воеводе Шеину, реестры расходов и различного имущества. По сделанным польскими секретарями пометкам мы узнаем, что в польский обиход входят тогда такие русизмы, как «грамота» («hramata») [30], «посадский люд» («ludzi posadzkich») [26], «монастырь» («manastir»), келарь («kiełar») [4], «окольничество» («okolńczestwo») [6], «монастырский расход» («monastyrski roschod») [32]. Наряду с традиционным для поляков наименованием Смоленского княжества «Смоленщина» («Smoleńszczyzna»), на московских докумен- 
тах довольно часто начинает встречаться польская пометка «Смоленская волость» («Smolenska włość») [9], а из иных традиционно московских терминов административнотерриториального деления встречается «Дорогобужский уезд» («Dorohobużski uiezd») [13].

Материалы и их исторический анализ. Помимо анализа сугубо лингвистического, возможно посмотреть на данные польские пометки и с точки зрения исторической. Особо подробно просматривались челобитные к королю и королевичу лиц, каклибо (по крайней мере с их слов) пострадавших от Василия Шуйского, на них обязательно делалась соответствующая пометка. Так, например, Григорий и Иван Ржевские просят вернуть им жалованье, на документе имеется пометка королевской канцелярии: «Сo był Szuiski odiął» («отнятое Шуйским») [16]. Подобные же уточнения имеются на челобитной Василия, Ивана и Лаврентия Ржевских [17], челобитной Ивана и Андрея Ржевских [18]. Думается, что жалобы на несправедливости низведенного с престола царя Василия сулили особую королевскую благосклонность, и прошения с соответствующими пометками рассматривались в пользу челобитчика. Примечательно, что в польских пометках имени Василия Шуйского никогда не предшествует его титул «царь», это также свидетельствует о презрительном и пренебрежительном настроении королевского двора к тогда уже плененному государю. В противоположность этому убитый Лжедмитрий I именуется в одной из пометок «царь Дмитрий» («car Dmitr») [5], а отнюдь не самозванец, поскольку в истории имел место быть эпизод поддержки польским королем его «прав» на престол. Интересно и отношение к второму самозванцу, Тушинскому или Калужскому вору. На «Расспросных речах романовских татар в московском стане об убиении в Калуге самозванца» стоит краткая пометка секретаря: «Новости из Калуги» («Nowiny z Kaługi»), что наверняка свидетельствует о том, что ничего нового из этого документа польская сторона не узнала, не уточняя и не называя даже имени погибшего «царика» (более подробно об отношении польской стороны и российских самозванцев отмечено в нескольких наших работах $[23 ; 24 ; 25])$.
Результаты. Таким образом, не изученные до настоящего времени польские пометки на документах московского происхождения времен Смуты свидетельствуют о большом влиянии русского делопроизводственного языка на польский язык, влиянии настолько сильном, что значительное количество русизмов используются в это время польской королевской канцелярией без попыток использования их перевода.

\section{СПИСОК ЛИТЕРАТУРЫ}

1. Акты исторические, собранные в библиотеках и архивах Российской империи археографической экспедицией императорской академии наук. СПб. : в Тип. 2-го отд-ния Собственной Е. И. В. канцелярии, 1836. - Т. 2. -385 с.

2. Выпись из росписей о хлебном жаловании // Архив СПбИИ РАН. - Кол. 174. - Оп. 2. Д. 326. - Л. 1.

3. Курдюмов, М. Г. Описание актов, хранящихся в архиве Археографической комиссии / М. Г. Курдюмов. - Петроград : Первая петрогр. труд. артель печатников, 1923. - С. 4.

4. Отписка Троицкого осадного воеводы князя Григория Долгорукова // Архив СПбИИ РАН. Кол. 124. - Оп. 1. - Д. 359. - Л. 1.

5. Отчинная грамота Андрею Тимофеевичу Быкасову на село Василево // Архив СПбИИ РАН. Кол. 121. - Оп. 1. - Д. 159. - Л. 1.

6. Письмо князя Федора Мстиславского литовскому канцлеру Льву Сапеге // Архив СПбИИ РАН. - Кол. 124. - Оп. 1. - Д. 435. - Л. 2.

7. Русская историческая библиотека, издаваемая Археографической комиссией. - СПб. : Археографическая комиссия, 1872-1927. - Т. 2 : [12911645 гг. / ред. А. И. Тимофеев]. - 1875. - 656 с.

8. Список смоленским дворянам и детям боярским по городу, воротам и башням для осадного времени // Архив СПбИИ РАН. - Кол. 124. Оп. 1. - Д. 361. - Л. 1.

9. Челобитная Борису Годунову Смоленских дворцовых крестьян Есенской волости // Архив СПбИИ РАН. - Кол. 124. - ОП. 1. - Д. 149. - Л. 1.

10. Челобитная дворцовых крестьян Дубровского стана Федора Данилова и Наума Федорова царю Борису Годунову // Архив СПбИИ РАН. Кол. 124. - Оп. 1.-Д. 151. - Л. 1.

11. Челобитная Ивана Горихвостова о пожаловании его поместьем // Архив СПбИИ РАН. Кол. 124. - Оп. 1.- Д. 469. - Л. 1.

12. Челобитная о пожаловании кормом // Архив СПбИИРАН. -Кол. 124. - Оп. 1.-Д. 467.-Л. 1. 
13. Челобитная Сигизмунду III Ивана Александровича Ржевского // Архив СПбИИ РАН. Кол. 124. - Оп. 1. - Д. 517. - Л. 1.

14. Челобитная Сигизмунду III смоленского купца Авксентия Дюкорева // Архив СПбИИ РАН. Кол. 124. - Оп. 1. - Д. 511. - Л. 1.

15. Челобитная Сигизмунду и Владиславу Григория Дымова о возвращении ему его поместья // Архив СПбИИ РАН. - Кол. 124. - Оп. 1. Д. 515. - Л. 1.

16. Челобитная Сигизмунду и Владиславу дворян Якова Григорьева и Ивана Петрова Ржевских // Архив СПбИИРАН. -Кол. 124.-Оп. 1.-Д. 429.-Л. 1.

17. Челобитная Сигизмунду и Владиславу дворянина Василия Матвеевича Ржевского // Архив СПбИИ РАН. - Кол. 124. - Оп. 1. - Д. 430. - Л. 1.

18. Челобитная Сигизмунду и Владиславу окольничего Ивана Николаевича Ржевского, вдовы Авдотьи Ржевской, Якова и Ивана Ржевских // Архив СПбИИ РАН. - Кол. 124. - ОП. 1. - Д. 520. - Л. 1.

19. Челобитная Сигизмунду и Владиславу смоленского дворянина Григория Кузьмича Пыхочева // Архив СПбИИ РАН. - Кол. 124. - Оп. 1. Д. 464. - Л. 1.

20. Челобитная Сигизмунду и Владиславу смолянина Федора Меньшого Перфурьева // Архив СПбИИ РАН. - Кол. 174. - ОП. 2. - Д. 500. - Л. 1.

21. Челобитная торгового человека Оверкия Сысоева Сигизмунду III // Архив СПбИИ РАН. Кол. 124. - Оп. 1. - Д. 147. - Л. 1.

22. Челобитная царю Владиславу Сигизмундовичу и королю польскому Сигизмунду Лаврентия Иванова и Ивана Александрова // Архив СПбИИ РАН. - Кол. 124. - Оп. 1. - Д. 428. - Л. 1.

23. Эйльбарт, Н. В. Лжедмитрий II: происхождение и гибель. Свидетельства польских документов Государственного архива Швеции / Н. В. Эйльбарт // Вестник Забайкальского государственного университета. - 2012. - № 11. - С. 3-10.

24. Эйльбарт, Н. В. Лжедмитрий I и политическая элита Речи Посполитой: мифы и факты / Н. В. Эйльбарт // Вестник Забайкальского государственного университета. - 2012. - № 12. - С. 19-27.

25. Эйльбарт, Н. В. Смутное время в польских документах Государственного архива Швеции. Комментированный перевод и исторический анализ / Н. В. Эйльбарт. - Новосибирск : Наука, 2013. - 401 с.

26. Riksarkivet, Skoklostersamlingen 3, Extranea. - Handlingar fren Smolensk, Nytt signum 02, PEA 10.

27. Riksarkivet, Skoklostersamlingen 3, Extranea. - Handlingar fren Smolensk, Gammalt signum E 8610: 04a, PEA 181.

28. Riksarkivet, Skoklostersamlingen 3, Extranea. - Handlingar fren Smolensk, Gammalt signum E 8610:21, PEA308.
29. Riksarkivet, Skoklostersamlingen 3, Extranea. - Handlingar fren Smolensk, Gammalt signum E 8610:16, PEA 522.

30. Riksarkivet, Skoklostersamlingen 3, Extranea. - Handlingar fren Smolensk, Gammalt signum E 8610:16, PEA 525.

31. Riksarkivet, Skoklostersamlingen 3, Extranea, E 8610 N:o 344. - Ryska brev, PEA 246.

32. Riksarkivet, Skoklostersamlingen 3, Extranea, E 8610 N:o 344. - Ryska brev, PEA 247.

\section{REFERENCES}

1. Akty istoricheskie, sobrannye v bibliotekakh $i$ arkhivakh Rossiyskoy imperii arkheograficheskoy ekspeditsiey imperatorskoy akademii nauk [Acts of History Collected in the Libraries and Archives of the Russian Empire by the Archaeological Expedition of the Imperial Academy of Sciences]. Saint Petersburg, v Tipografii 2-go otdeleniya Sobstvennoy E. I. V. kantselyarii, 1836, vol. 2. 385 p.

2. Vypis iz rospisey o hlebnom zhalovanii [List of Those Who Were Given a Salary Bread]. Arkhiv SpbII RAN [Archive of Saint Petersburg Institute of History of the Russian Academy of Sciences], Collection 174, Op. 2, D. 326, L. 1.

3. Kurdyumov M.G. Opisanie aktov, khranyashchikhsya $v$ arkhive Arkheograficheskoy komissii [Description of Acts Stored in the Archives of the Archaeographic Commission]. Petrograd, Pervaya petrogradskaya trudovaya artel pechatnikov, 1923, p. 4.

4. Otpiska Troitskogo osadnogo voevody knyazya Grigoriya Dolgorukova [The Letter of Siege Voivode Prince Grigory Dolgoruky]. Arkhiv SpbII RAN [Archive of Saint Petersburg Institute of History of the Russian Academy of Sciences], Collection 124, Op. 1, D. 359, L. 1.

5. Otchinnaya gramota Andreyu Timofeevichu Bykasovu na selo Vasilevo [Privilege to Andrei Timofeevich Bykasov for the Village of Vasilevo]. Arkhiv SpbII RAN [Archive of Saint Petersburg Institute of History of the Russian Academy of Sciences], Collection 121, Op. 1, D. 159, L. 1.

6. Pismo knyazya Fedora Mstislavskogo litovskomu kantsleru Lvu Sapege [Letter from Prince Fedor Mstislavsky to the Lithuanian Chancellor Lev Sapieha]. Arkhiv SpbII RAN [Archive of Saint Petersburg Institute of History of the Russian Academy of Sciences], Collection 124, Op. 1, D. 435, L. 2.

7. Timofeev A.I., ed. Russkaya istoricheskaya biblioteka, izdavaemaya Arkheograficheskoy komissiey. T. 2. 1291-1645 gg. [Russian Historical Library Published by the Archaeographic Commission. 
Vol. 2. 1291-1645]. Saint Petersburg, Arkheograficheskaya komissiya Publ., 1875. 656 p.

8. Spisok smolenskim dvoryanam i detyam boyarskim po gorodu, vorotam i bashnyam dlya osadnogo vremeni [List to Smolensk Nobles and Boyars' Children by City, Gate and Towers for the Siege Time]. Arkhiv SpbII RAN [Archive of Saint Petersburg Institute of History of the Russian Academy of Sciences], Collection 124, Op. 1, D. 361, L. 1.

9. Chelobitnaya Borisu Godunovu Smolenskikh dvortsovykh krestyan Esenskoy volosti [Petition to Boris Godunov from Smolensk Palace Peasants of Esnenskaya Volost]. Arkhiv SpbII RAN [Archive of Saint Petersburg Institute of History of the Russian Academy of Sciences], Collection 124, Op. 1, D. 149, L. 1.

10. Chelobitnaya dvortsovykh krestyan Dubrovskogo stana Fedora Danilova i Nauma Fedorova tsaryu Borisu Godunovu [Petition from Palace Peasants Fedor Danilov and Naum Fedorov to Tsar Boris Godunov]. Arkhiv SpbII RAN [Archive of Saint Petersburg Institute of History of the Russian Academy of Sciences], Collection 124, Op. 1, D. 151, L. 1.

11. Chelobitnaya Ivana Gorikhvostova o pozhalovanii ego pomestyem [Petition of Ivan Gorikhvostov on His Award with the Estate]. Arkhiv SpbII RAN [Archive of Saint Petersburg Institute of History of the Russian Academy of Sciences], Collection 124, Op. 1, D. 469, L. 1.

12. Chelobitnaya o pozhalovanii kormom [Petition on the Award with Feed]. Arkhiv SpbII RAN [Archive of Saint Petersburg Institute of History of the Russian Academy of Sciences], Collection 124, Op. 1, D. 467, L. 1.

13. Chelobitnaya Sigizmundu III Ivana Aleksandrovicha Rzhevskogo [Petition to Sigismund III from Ivan Alexandrovich Rzhevsky]. Arkhiv SpbII $R A N$ [Archive of Saint Petersburg Institute of History of the Russian Academy of Sciences], Collection 124, Op. 1, D. 517, L. 1.

14. Chelobitnaya Sigizmundu III smolenskogo kuptsa Avksentiya Dyukoreva [Petition to Sigismund III from Smolensk Merchant Avksentiy Dyukorev]. Arkhiv SpbII RAN [Archive of Saint Petersburg Institute of History of the Russian Academy of Sciences], Collection 124, Op. 1, D. 511, L. 1.

15. Chelobitnaya Sigizmundu i Vladislavu Grigoriya Domozhirova o vozvrashchenii emu ego pomestya [Petition to Sigizmund and Vladislav from Grigoriy Domozhirov on the Return of His Estate to him]. Arkhiv SpbII RAN [Archive of Saint Petersburg Institute of History of the Russian Academy of Sciences], Collection 124, Op. 1, D. 515, L. 1.

16. Chelobitnaya Sigizmundu i Vladislavu dvoryan Yakova Grigoryeva i Ivana Petrova Rzhevskikh [Petition to Sigismund and Vladislav from
Nobles Jacob Grigoryev and Ivan Petrov Rzhevsky]. Arkhiv SpbII RAN [Archive of Saint Petersburg Institute of History of the Russian Academy of Sciences], Collection 124, Op. 1, D. 429, L. 1.

17. Chelobitnaya Sigizmundu i Vladislavu dvoryanina Vasiliya Matveevicha Rzhevskogo [Petition to Sigismund and Vladislav from Noble Vasiliy Matveevich Rzhevsky]. Arkhiv SpbII RAN [Archive of Saint Petersburg Institute of History of the Russian Academy of Sciences], Collection 124, Op. 1, D. 430, L. 1.

18. Chelobitnaya Sigizmundu i Vladislavu okolnichego Ivana Nikolaevicha Rzhevskogo, vdovy Avdoti Rzhevskoy, Yakova i Ivana Rzhevskikh [Petition to Sigismund and Vladislav from Okolnichy Ivan Nikolayevich Rzhevsky, Widow Avdotya Rzhevskaya, Jacob and Ivan Rzhevsky]. Arkhiv SpbII RAN [Archive of Saint Petersburg Institute of History of the Russian Academy of Sciences], Collection 124, Op. 1, D. 520, L. 1.

19. Chelobitnaya Sigizmundu i Vladislavu smolenskogo dvoryanina Grigoriya Kuzmicha Pykhocheva [Petition to Sigismund and Vladislav from Smolensk Noble Grigoriy Kuzmich Pykhochev]. Arkhiv SpbII RAN [Archive of Saint Petersburg Institute of History of the Russian Academy of Sciences], Collection 124, Op. 1, D. 464, L. 1.

20. Chelobitnaya Sigizmundu i Vladislavu smolyanina Fedora Menshogo Perfureva [Petition to Sigismund and Vladislav from Smolensk Citizen Fyodor Menshy Perfuryev]. Arkhiv SpbII RAN [Archive of Saint Petersburg Institute of History of the Russian Academy of Sciences], Collection 174, Op. 2, D. 500, L. 1.

21. Chelobitnaya torgovogo cheloveka Overkiy Sysoev Sigizmundu III [Petition of Trade Man Overkiy Sysoev to Sigismund III]. Arkhiv SpbII RAN [Archive of Saint Petersburg Institute of History of the Russian Academy of Sciences], Collection 124, Op. 1, D. 147, L. 1.

22. Chelobitnaya tsaryu Vladislavu Sigizmundovichu i korolyu polskomu Sigizmundu Lavrentiya Ivanova i Ivana Aleksandrova [Petition to Tsar Vladislav Sigismundovich and Polish King Sigismund from Lavrentiy Ivanov and Ivan Aleksandrov]. Arkhiv SpbII $R A N$ [Archive of Saint Petersburg Institute of History of the Russian Academy of Sciences], Collection 124, Op. 1, D. 428, L. 1.

23. Ejl'bart N.V. Lzhedmitriy II: proiskhozhdenie i gibel. Svidetelstva polskikh dokumentov Gosudarstvennogo arkhiva Shvetsii [The False Dmitri II: the Origin and the Death. Evidence of Polish Documents of Riksarkivet]. Vestnik Zabaykalskogo gosudarstvennogo universiteta [Transbaikal State University Journal], 2012, no. 11, pp. 3-10.

24. Ejl'bart N.V. Lzhedmitriy I i politicheskaya elita Rechi Pospolitoy: mify i fakty [The False Dmitri I and Political Elite of Polish-Lithuanian Commonwealth: Myths and Facts]. Vestnik Zabaykalskogo 
H.В. Эйльбарт. Польские пометки на московских документах периода Смуты

gosudarstvennogo universiteta [Transbaikal State University Journal], 2012, no. 12, pp. 19-27.

25. Ejl'bart N.V. Smutnoe vremya v polskikh dokumentakh Gosudarstvennogo arkhiva Shvetsii. Kommentirovannyy perevod $i$ istoricheskiy analiz [The Time of Troubles in Polish Documents of the State Archives of Sweden. Annotated Translation and Historical Analysis]. Novosibirsk, Nauka Publ., 2013. 401 p.

26. Riksarkivet, Skoklostersamlingen 3, Extranea, Handlingar fren Smolensk, Nytt signum 02, PEA 10.

27. Riksarkivet, Skoklostersamlingen 3, Extranea, Handlingar fren Smolensk, Gammalt signum E 8610: 04a, PEA 181.
28. Riksarkivet, Skoklostersamlingen 3, Extranea, Handlingar fren Smolensk, Gammalt signum E 8610:21, PEA 308.

29. Riksarkivet, Skoklostersamlingen 3, Extranea, Handlingar fren Smolensk, Gammalt signum E 8610:16, PEA 522.

30. Riksarkivet, Skoklostersamlingen 3, Extranea, Handlingar fren Smolensk, Gammalt signum E 8610:16, PEA 525.

31. Riksarkivet, Skoklostersamlingen 3, Extranea, E 8610 N:o 344 Ryska brev, PEA 246.

32. Riksarkivet, Skoklostersamlingen 3, Extranea, E 8610 N:o 344 Ryska brev, PEA 247.

\section{Information about the Author}

Natalia V. Eilbart, Doctor of Sciences (History), Associate Professor, Professor, Department of Russian History, Herzen State Pedagogical University of Russia, Reki Moyki Emb., 48, 191186 Saint Petersburg, Russian Federation, ejlbart@mail.ru, https://orcid.org/0000-0001-7967-8014

\section{Информация об авторе}

Наталия Владимировна Эйльбарт, доктор исторических наук, доцент, профессор кафедры русской истории, Российский государственный педагогический университет им. А.И. Герцена, наб. p. Мойки, 48, 191186 г. Санкт-Петербург, Российская Федерация, ejlbart@mail.ru, https:// orcid.org/0000-0001-7967-8014 